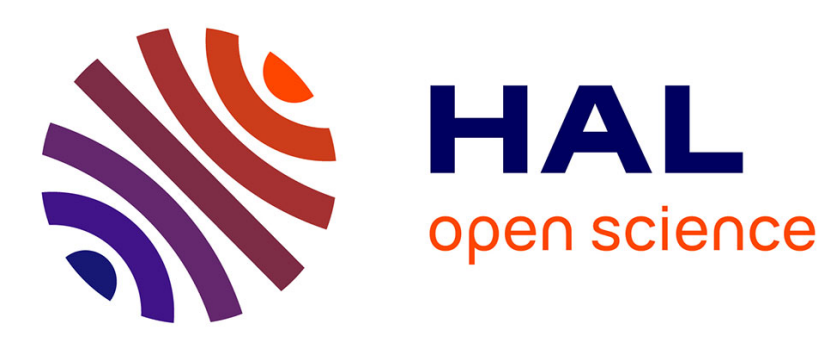

\title{
Electric Field Dependent Switching in Li-Cd Ferrites
}

\author{
M. Sagare, M. Vaingankar, S. Kulkarni
}

\section{To cite this version:}

M. Sagare, M. Vaingankar, S. Kulkarni. Electric Field Dependent Switching in Li-Cd Ferrites. Journal de Physique IV Proceedings, 1997, 07 (C1), pp.C1-157-C1-158. 10.1051/jp4:1997156 . jpa-00255103

\section{HAL Id: jpa-00255103 https://hal.science/jpa-00255103}

Submitted on 1 Jan 1997

HAL is a multi-disciplinary open access archive for the deposit and dissemination of scientific research documents, whether they are published or not. The documents may come from teaching and research institutions in France or abroad, or from public or private research centers.
L'archive ouverte pluridisciplinaire HAL, est destinée au dépôt et à la diffusion de documents scientifiques de niveau recherche, publiés ou non, émanant des établissements d'enseignement et de recherche français ou étrangers, des laboratoires publics ou privés. 


\title{
Electric Field Dependent Switching in Li-Cd Ferrites
}

\author{
M.S. Sagare, M.S. Vaingankar* and S.G. Kulkarni** \\ $B V$ 's ASC College, Sangli 416416 , India \\ *Shivaji University, Kolhapur 416004 , India \\ ** Willingdon College, Sangli 416415 , India
}

\begin{abstract}
Stoichiometric Lithium-Cadmium Polycrystalline Ferrite System $\left(\mathrm{Li}{ }_{0.5} \mathrm{Fe}_{0.5}\right)_{1-x} \mathrm{Cd}_{\mathrm{x}} \mathrm{Fe}_{2} \mathrm{O}_{4}$, prepared by standard ceramic route exhibits CCNR- type electrical switching, when the field is applied across the material in the pellet form. The importance of the result is that the property is exhibited by the material which is furnace cooled and is not submitted to any additional thermal treatment. Further, the switching is observed at room temperature $\left(25^{\circ} \mathrm{C}\right)$ and at relatively low fields. The addition of $\mathrm{Cd}^{++}$just by $\mathrm{X}=0.1$ reduces the requirement of field drastically, however, further addition of $\mathrm{Cd}$-content reverses the trend. The I-V characteristics are similar to those of three junction four layer semiconductor structure and there is no aging effect. The phenomenon is observed in all the compositions of the series irrespective of ferri or paramagnetic in nature. The system provides exception to the proposed models and therefore, no fully satisfactory explanation of this property looks to be possible at this stage, however, the experimental results will be important as it will lead to developing electrical switching devices.
\end{abstract}

\section{INTRODUCTION}

Many ferri magnetic materials are poor conductors of electricity, a quality exploited in device applications. Presently one of the important applications of ferrites is in the field of memory and switching devices, like digital computers and data processing circuits, based on the use of microsecond pulses transmitting, storing and reading information in a binary code.

\subsection{EXPERIMENTAL}

$\left(\mathrm{Li}_{05} \mathrm{Fe}_{05}\right)_{1-x} \mathrm{Cd}_{*} \mathrm{Fe}_{2} \mathrm{O}_{4}$ ferrite system was prepared by standard ceramic technique and single phase compound preparation was confirmed by XRD, IR and SEM techniques. All the compounds in the peller form of $1 \mathrm{~cm}$ diameter were subjected to I-V measurements.

\subsection{CONDUCTION MECHANISM}

A number of oxide films and semi-insulating materials exhibit electircal switching and memory phenomena. The resistivity of ferries is of the order of semiconductors to insulators and though they exhibit negative temperature coefficient of resistance, the conduction in ferrites is not similar to that of semiconductors. In ferrites conduction depends on mobility of charges which increases with the increase of temperature without change in charge concentration. The I-V characteristics which are exhibited by this Li-Cd ferrite system is very similar to the switching in thyristor which is three junction four layer diode.

\section{RESULTS AND DISCUSSION}

In this Li-Cd ferrite system each of the compositions exhibits electrical switching. Initially current obeys Ohms' Law and then current suddenly increases to a high value at breakdown voltage. We have obtained these results for slow cooled $\mathrm{Li}$-Cd samples $\left(\mathrm{M}_{0}-\mathrm{M}_{10}\right)$ that too at room temperature. That is the importance of this work. Yamashiro [1] has reported electrical switching phenomenon in case of $\mathrm{CuFe}_{2} \mathrm{O}_{4}$ and he attributed it to Jahn-Teller distortion transformation. Histake et.al [2] have reported switching action in $\mathrm{Li}$-ferrite and they attributed it to Joule-Self heating. Ferrites such as $\mathrm{Mg}-\mathrm{Mn}$ exhibit similar type of behaviour [3]. Vaingankar et. al [4,5] have reported structual transformation during electrical switching and have discussed in detail that the probable cause of electrical switching in ferrites varies with the system under investigation. 


\subsection{I-V CHARACTERISTICS}

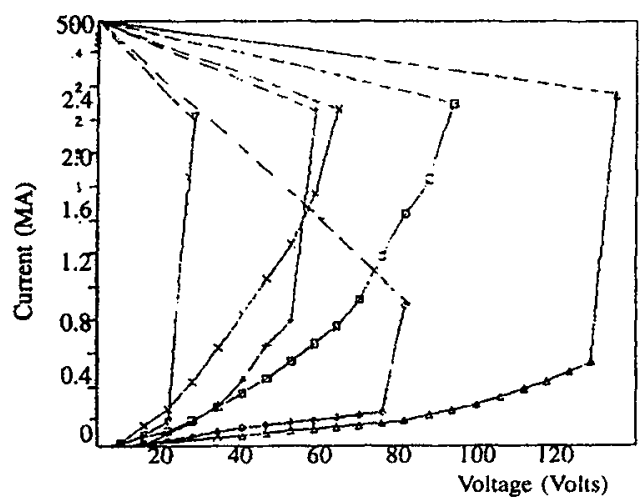

Ferrimagnetic samples $M_{0}-M_{5}$ $\nabla M_{0} \quad \nabla M_{1}+M_{2} \quad \diamond M_{3} \quad \Delta M_{4} \quad M_{5}$

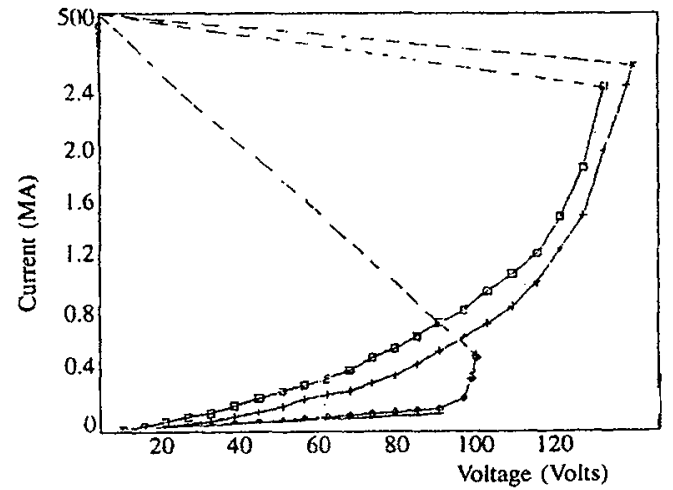

Paramagnetic samples $M_{6}-M_{10}$

a $\mathrm{M}_{6}+\mathrm{M}_{8} O \mathrm{M}_{10}$

Fig. 2

Fig. 1

The electrical switching in different ferrites reported by all the above workers occurs at elevated temperatures and they have putforth different causes which do not look to be applicable to the present system, except the self heating which is obvious, because when the second switching cycle was repeated imediately after the first cycle, it was observed that the switching occurs at lower electric field. No aging effect was observed. As none of the arguments suits to our ferrite system, we tried to observe the SCL, currents in the system. There is possibility, according to band theory of insulators, that additional carriers are injected by metal electrodes though the metal insulator contact. If the injected carrier - density becomes more than free carrier density, then SCL-currrent flows. This can be inspected by graphs $\log$ I Vs $\log$ V which show that at low voltage current obeys Ohms' Law and at breakdown voltage the slope of this curve increases, indicating existence of SCL-currents which could becited as the possible cause of electrical switching in the present system. This is also the essential feature of CCNR-type of electrical switching.

\section{CONCLUSION}

Though none of the models can satisfactorily explain the electrical switching in the present Li-Cd ferrite system, the results which are obtained in the furnace cooled compounds at room temperature turn out to be important as they can have immediate application in the device development.

\section{Reference}

1.Yamashiro T. Japn. J. Appl. Phys., Japan 12 (1973),pp 146-148

2.Histake K., Nakayama K. \& Ohta K., Japan, Appl. Phys. 12 (1973), pp-1116

3.Kapalan J., Bullock D.C., Adler D. \& Epstein D.J., Appl. Phys. Letts. 20(1972), pp-439.

4.Vaingankar A.S., Patil S.A., Todkar M.M., Khot A.Y. \& Devale V.B., NP \& SSP Symp., 23C (1980), pp-250.

5.Vaingankar A.S., Kamble P.N. \& Kulkarni V.R., Indian J. of Pure and Appl. Phys. 28 (1990) pp-508. 